\title{
Trabalhonecessário
}

Issn: 1808 - 799X

ano 13, número $20-2015$

\section{SABERES DO TRABALHO: SITUANDO O TEMA NO CAMPO TRABALHO-EDUCAÇÃO}

\author{
Naira Lisboa Franzoi ${ }^{1}$ \\ Maria Clara Bueno Fischer²
}

\section{Resumo}

O objetivo do texto é realizar uma genealogia do tema saberes do trabalho, pontuando-se, sempre que pertinente, sua inserção na história do GT TrabalhoEducação, da Anped. O estudo baseou-se em estados da arte do campo Trabalho-Educação e em pesquisas que tomam como objeto específico de análise o próprio tema saberes do trabalho. Chama-se a atenção para a potência e limites das análises realizadas nos anos 90. Abordam-se pesquisas que, procurando superar tais limites, utilizam conceitos marxianos em diálogo com outras vertentes. Ao final, pontuam-se os conceitos explorados e os que merecem aprofundamento.

Palavras-chave: Trabalho-Educação, Saberes do Trabalho, Experiência de Trabalho

\footnotetext{
1 Professora da Faculdade de Educação da Universidade Federal do Rio Grande do Sul. Coordenadora do projeto de pesquisa "Trajetórias, saberes e identidades profissionais", Porto Alegre: UFRGS. Apoio FAPERGS. Email: naira.lisboa.franzoi50@gmail.com

2 Professora da Faculdade de Educação da Universidade Federal do Rio Grande do Sul. Coordenadora do projeto de pesquisa "Formação de adultos para e no trabalho associado: atividade de trabalho, profissão e biografias". Apoio CNPq. Email: clarafis@cpovo.net
} 
Issn: 1808 - 799X

ano 13, número $20-2015$

\begin{abstract}
The purpose of the paper is to present a genealogy of the theme working knowledge, pointing up, where appropriate, their inclusion in the history of GT Work and Education (ANPED - National Association of Research on Education). The study was based on studies of state of the art produced in the Work and Education field and also on researches that take as their specific purpose of analysis the theme of working knowledge. It calls attention to the power and limits of the analysis carried out in the $90 \mathrm{~s}$ It addresses researches that, seeking to overcome such limits, use Marxist concepts in dialogue with other perspectives. Finally, it is punctuated the concepts used and those which demand to be develped.
\end{abstract}

Key-words: Work and Education, Working Knowlegde, Work Experience

Este artigo traz reflexões apresentadas na mesa Culturas do trabalho, movimentos sociais e produção de saberes ${ }^{3}$ que integrou a programação do II Intercrítica, em agosto de 2014. Consoante com o Encontro, uma das contribuições da mesa foi realizar um balanço do tema saberes do trabalho ${ }^{4}$, pontuando-se, sempre que pertinente, sua inserção na história do GT TrabalhoEducação, da Associação Nacional de Pesquisa e Pós Graduação em Educação (Anped). Para tal, foi necessário retomar e analisar caminhos, tempos e espaços

3 O artigo compila e amplia as exposições das autoras, que focaram o tema Saberes do Trabalho. A mesa contou também com a participação de Lia Tiriba, cuja reflexão privilegia uma análise dos sujeitos-trabalhadores, sua cultura, seu trabalho e suas experiências de classe e é apresentada em outro artigo deste mesmo dossiê.

4 Entendemos saberes do trabalho como aqueles produzidos, mobilizados e modificados em situação de trabalho. O termo saber, segundo Santos (2000), é tomado como sinônimo de conhecimento, "no entanto, a opção por um ou outro tem implicações de várias ordens. Conhecimento é utilizado quando se quer referir ao saber científico, ou ao saber formalizado, socialmente legitimado. Já o saber, via de regra, tem uma conotação mais pejorativa [...]. No entanto, um debate atual, coloca na ordem do dia a necessidade de resgatar as dimensões esquecidas dos saberes chamados menores elevando-os à maioridade" (p. 295). É no contexto deste debate que se situa nossa problemática. As pesquisas trazidas no texto exploram tais dimensões tomando como foco o sujeito na relação com o seu trabalho. 


\section{Trabalhonecessário}

Issn: 1808 - 799X

ano 13, número $20-2015$

de produção das ideias que circulam na área. Ainda consoante com o II Intercrítica, buscou-se interrogar a atual agenda de estudos e debates do GT para contribuir na instauração ou retomada de outras, a partir de lacunas detectadas.

Adverte-se que o balanço não foi exaustivo, o que não seria possível no escopo da mesa ou do próprio artigo, mas se realizou a partir de abordagens que têm estado presentes em nossas trajetórias de pesquisadoras, a partir das quais temos estabelecido interlocuções através de nosso grupo de pesquisa ${ }^{5}$.

\section{Emergência do Tema: a Educação do Trabalhador "Para Além dos Muros da Escola"}

$\mathrm{Na}$ década de 80, uma forte tendência uniu teóricos de diferentes campos em torno do mundo do trabalho. Na área da educação, a perspectiva de análise reprodutivista dos anos 70-80, se, por um lado, engessa a escola, por outro como, nos lembra Santos - leva-a "a repensar-se para além dos seus próprios muros, inserida em relações sociais mais amplas, trazendo para o debate a luta capital-trabalho" (Santos, 2000, p. 120).

O grupo Trabalho e Educação da Anped, em sua fundação - 1981 expressa tais preocupações quando aponta ${ }^{6}$ :

a vinculação entre educação e processo produtivo posta pela política educacional a partir de 70 , expressa na legislação: - o aprofundamento das relações entre escola e trabalho, decorrente das imposições do capital, que determina cada vez mais, o tipo de escola demandada, na qual esbarram os projetos educacionais alternativos; - a luta pela escola e por um projeto popular de educação como decorrência do movimento de organização da classe trabalhadora (Arroyo apud Kuenzer, 1986, p. 49).

5 Trata-se do Grupo Trabalho, Educação e Conhecimento (Base Diretório CNPq).

6 São reflexões postas por Miguel Arroyo (1981) para os pesquisadores à época da criação do GT que, segundo Kuenzer (1986), captava elementos essenciais das preocupações dos pesquisadores naquele momento. 
Issn: 1808 - 799X

ano 13 , número $20-2015$

Neste sentido, vários temas de investigação são indicados ${ }^{7}$. Entre eles chamamos a atenção para três que indicam as preocupações do Grupo em pesquisar a Educação do Trabalhador, em particular o tema dos saberes na relação capital-trabalho:

- ciência, educação e processo de produção e trabalho, com o objetivo de estudar o processo de produção-reproduçãoexpropriação-apropriação do saber pelo capital, de modo a compreender como se dá a produção social do saber, quais os processos que o reproduzem; como o capital se apropria do saber técnico-científico e do saber do trabalhador, como a qualificação, a ciência e a técnica são utilizadas pelo capital no processo de criação de valor;

- educação e divisão social de trabalho a partir da constatação da distribuição cada vez mais desigual do saber entre técnicos especializados e trabalhadores em geral; investigar os mecanismos de exclusão do saber dos produtores diretos, priorizando a relação entre trabalho e não-educação, como um fenômeno mais presente na história das relações de trabalho ao invés de priorizar a relação positiva entre trabalho e educação;

- educação e formação da classe operária, com o objetivo de investigar a relação entre educação e formação/emancipação da classe operária, para identificar a dimensão política do processo de reapropriação do saber pelo trabalhador na sua constituição enquanto cidadão, para isso, investigar não só a contribuição da escola, mas todos os processos de "auto-educação" que ocorrem através das experiências sociais e de trabalho, "por dentro" da classe trabalhadora (Arroyo apud Kuenzer, 1986, p. 50, grifo nosso).

Em 1986, em seminário de pesquisadores da área, o GT chega a uma fundamental conclusão:

A área estava padecendo de uma inversão ao tomar a educação
como ponto de partida para a análise - tomando como base os
princípios da crítica à economia política - o fato que nesta, a
dimensão trabalho constitui-se como categoria central da qual se
parte para a compreensão do fenômeno educativo e das

7 Educação e trabalho na política educacional; educação, trabalho e igualdade social; história da relação educação e trabalho no Brasil; como se "forma-fabrica" o trabalhador no Brasil; ciência, educação e processo de produção e trabalho; educação e divisão social de trabalho; educação e formação da classe operária. 


\section{Trabalhonecessário}

Issn: 1808 - 799X

ano 13 , número $20-2015$

articulações recíprocas entre estas duas dimensões - educação e trabalho (Kuenzer, 1991, p. 92).

Assim, a inversão de educação e trabalho para trabalho e educação foi assumida pelos investigadores, mantendo-se até hoje. O trabalho é o princípio primeiro para se entender a sociedade e, portanto, a educação. Tal marco é central para as pesquisas que se realizarão a partir daí, sobre os saberes do trabalho. Ainda neste mesmo seminário, os temas que se referiam a investigações já em andamento ou como possibilidade de pesquisa, são agrupados em categorias, algumas em definição desde o referido encontro:

a) Trabalho e educação - teoria e história: o trabalho como princípio educativo; a evolução histórica do conceito de trabalho; a relação trabalho e educação e sua reconstrução histórica.

b) Trabalho e educação básica: o trabalho e a continuidade/descontinuidade da escolarização do trabalhador; 0 mundo do trabalho, a escola e a formação científico-tecnológica do trabalhador.

c) Profissionalização e trabalho: a análise histórica das políticas de profissionalização definidas pelo Estado; trabalho, conhecimento e cidadania para a emancipação do trabalhador.

d) Educação do trabalhador nas relações sociais de produção: reestruturação produtiva, apropriação do conhecimento nos processos produtivos; a organização da produção e suas propostas pedagógicas; a escola, o trabalho, a sociedade e a construção da hegemonia.

e) Trabalho e educação nos movimentos sociais: a construção de identidades de diferentes categorias de trabalhadores; demandas de conhecimentos científico-tecnológicos dos movimentos sociais com base na produção; a ação pedagógica nas formas cooperativistas de organização dos trabalhadores (Trein; Ciavatta, 2003, p. 145, grifo nosso).

Como se pode perceber nos destaques ao longo da citação, as relações entre conhecimento e trabalho, tomando como base fundante o "trabalho como princípio educativo", perpassam as temáticas de investigação e dizem respeito ao tempo-espaço do trabalho e ao da educação e de suas inter-relações. A matriz do materialismo histórico e dialético, acompanhada da perspectiva da construção de hegemonia, orienta o GT nas formulações a respeito da Educação do 
Issn: 1808 - 799X

ano 13, número $20-2015$

Trabalhador, sendo paradigmática a produção teórica publicada no livro de Gomez et al. (1987). Trabalho e conhecimento: dilemas na educação do trabalhador.

Essas elaborações teórico-metodológicas e políticas, e de identidade de pesquisadores da área trabalho e educação, particularmente do próprio GT, serão um berço fundante de caminhos de produção de ideias sobre saberes do trabalho.

Na Pedagogia da Fábrica - obra paradigmática de Acácia Kuenzer - ela afirma a apropriação do saber sobre o trabalho como um direito do trabalhador ${ }^{8}$. A autora chamava a atenção para o fato de que a reduzida clareza que se tem sobre o processo de produção e de distribuição do conhecimento na sociedade dificulta a compreensão do papel da escola na (re)produção do saber sobre o trabalho, fazendo com que se confunda - e esta é a primeira falácia que precisa ser desmistificada - "a relação entre educação e trabalho com a relação escola e trabalho, como se o processo de produção e reprodução do conhecimento ocorresse no seu interior" (Kuenzer, 1986, p. 21).

O saber não é produzido na escola, mas no interior das relações sociais em seu conjunto; é uma produção coletiva dos homens em sua atividade real, enquanto produzem as condições necessárias à sua existência através das relações que estabelecem com a natureza, com outros homens e consigo mesmos [...]. Desta forma, o trabalho é a categoria que se constitui no fundamento do processo de elaboração do conhecimento (Marx e Engels, s.d. 24 a 27) [...]. O lócus, portanto, da produção do conhecimento é o conjunto das relações sociais. São inúmeras as formas de produção e distribuição resultantes do confronto cotidiano do homem com a natureza e com os seus pares que lhe apresenta questões que o obriga a desenvolver formas próprias de pensar e fazer experimentando, discutindo, analisando, descobrindo. A escola é apenas uma parte, e não a mais importante, neste conjunto de relações responsáveis pela produção e distribuição do conhecimento (Kuenzer, 1986, p. 21-22).

8 Esta afirmação é o título de outro texto de sua autoria: A apropriação do saber sobre o trabalho: um direito do trabalhador. Em Aberto: Brasília, ano 5, n. 30, abr./jun. 1986 
Issn: 1808 - 799X

ano 13, número $20-2015$

Tal concepção tem sua materialidade no projeto Jorge $\mathrm{Hage}^{9}$, que expressa os debates (e embates) educacionais da época e que permanecerá na LDB, de 1996: "A educação abrange os processos formativos que se desenvolvem na vida familiar, na convivência humana, no trabalho, nas instituições de ensino e organizações da sociedade civil e nas manifestações culturais".

Porém, mais do que o mundo do trabalho, o processo de trabalho é o que é central na produção dos saberes e, num sentido mais alargado, nas pedagogias do trabalho. Interessa saber como o trabalhador está sendo educado na fábrica capitalista.

\begin{abstract}
É preciso considerar, no entanto, que a superação da divisão do trabalho característica do modo de produção capitalista, exige uma "nova forma de organização do trabalho", exige ao mesmo tempo "uma nova concepção do trabalho". Esta mudança tem que se dar dialeticamente ao nível da estrutura - relações de produção e formas de organização do trabalho - e da superestrutura concepção nova de trabalho que tenha em vista a superação do trabalho alienado. Esta forma de ver a questão coloca a pedagogia do trabalho, manifestação superestrutural de determinada forma de organização da produção, como uma categoria que pode ser importante tanto para a conservação das relações de produção capitalistas quanto para a sua superação, inscrevendo-se, desta forma, no quadro da hegemonia. [...] Estas novas formas de organização e de concepção de trabalho vão sendo gestadas pelo e no próprio interior do processo de trabalho capitalista, fragmentado e heterogerido, com a pedagogia que lhe é peculiar; é aí que, lenta e contraditoriamente, vão surgindo as formas de superação (Kuenzer, 1986, p. 14-15).
\end{abstract}

Outro aspecto que nos chama atenção nas ideias desta autora são suas reflexões a respeito das dimensões teóricas e criativas do "trabalho enquanto acontecendo". Diz Kuenzer: "tem-se que admitir que há uma dimensão teórica e, portanto, criativa e transformadora, no saber elaborado na prática" (1991, p. 59). No entanto, a autora adverte que isso não deve ser confundido com "o saber

9 Dos debates organizados pelo Fórum Nacional em Defesa da Escola Pública, lançado em 1987, que eram abertos e com a participação da sociedade civil, nasceu a primeira de duas propostas para a LDB, que ficou conhecida como Projeto Jorge Hage. Esta representava os anseios da sociedade civil. 


\section{Trabalhonecessário}

Issn: 1808 - 799X

ano 13, número $20-2015$

sistematizado sob a forma de teoria". Acácia Kuenzer associa o saber da prática do trabalho ao senso comum e defende o acesso à ciência, à teoria e ao conhecimento escolar na Educação do Trabalhador.

\section{A Reestruturação Produtiva nos anos 90 e a Busca pelo Trabalhador "Sujeito" e seus Saberes}

A reestruturação produtiva capitalista de inspiração japonesa, com sua proclamada valorização da subjetividade do trabalhador, traz novos desafios ao debate. E, aspecto fundamental nessa subjetividade, é a produção dos saberes pelos trabalhadores em situação de trabalho, na perspectiva da valorização do capital. No GT Trabalho e Educação algumas pesquisas serão realizadas.

O tema da educação dos trabalhadores perante às novas exigências da reestruturação produtiva em curso está presente de 1996 a 2001, embora com incidência progressiva em relação à compreensão do saber dos trabalhadores e às políticas de formação (empresários e trabalhadores) (Trein; Ciavatta, 2003, p. 145, grifo nosso).

Alguns de nós, neste contexto, realizamos um profícuo encontro com outros campos teóricos que têm o processo de trabalho como objeto de estudo. Daí nosso diálogo com a engenharia da produção, os estudos sobre saúde do trabalhador, a ergonomia e, mais tarde, a ergologia. Estas duas últimas tiveram como principal fonte os estudos de Ivar Odone e seu grupo junto à Fiat italiana. Trazem como ferramentas teórico-metodológicas a Comunidade Científica Ampliada (Odone, 2007) e o Dispositivo Dinâmico a Três Polos (Durrive; Schwartz, 2008) para conhecer o trabalho com os trabalhadores, com vistas a seu empoderamento ${ }^{10}$. Os mapas de risco propostos por Odone chegaram aos

10 Neste sentido Hélder Pordeus Muniz, Jussara Brito, Kátia Reis de Souza, Milton Athayde, Marianne Lacomblez (2013) trazem rica reflexão no artigo "A contribuição de Ivar Oddone e sua 


\section{Trabalhonecessário}

Issn: 1808 - 799X

ano 13 , número $20-2015$

sindicatos brasileiros como uma das formas de intervir nos espaços de trabalho, em especial na indústria, para construir espaços de hegemonia na fábrica. Nosso encontro com esses outros campos se dá na medida em que somos convocadas pelos sindicatos. Para o sindicalismo brasileiro - o novo sindicalismo - foi o tempo das Organizações por Local de Trabalho: o processo de trabalho como lócus privilegiado da sua luta.

Como dissemos anteriormente, uma das dimensões fundamentais da reestruturação produtiva foi a valorização da subjetividade e, particularmente, do saber do trabalhador. Este saber não era novidade: por parte dos trabalhadores, foi sempre explicitado através das greves-padrão. Por parte do capital, através de instrumentos utilizados ao longo do tempo para dele se apropriar, sendo o próprio taylorismo um deles. No Modelo Japonês ${ }^{11}$ há uma mudança na concepção de produção do conhecimento dos trabalhadores em relação ao taylorismo. Para este, o conhecimento podia ser transferido num determinado momento: acreditava-se que, a partir do momento em que ele se transformasse em padrão, ele estaria nas mãos do capital. O Modelo Japonês, ao contrário, concebe o conhecimento como um processo que se dá em ato e é produzido permanentemente, sendo sua verdadeira novidade a explicitação do reconhecimento e a legitimação do saber pelo capital (Freyssenet; Hirata, 1985).

Não se pode desconhecer, no entanto, que os saberes dos trabalhadores no chão de fábrica se desenvolvem dentro de um quadro de separação histórica entre concepção e execução do trabalho. Porém, se o saber prático do trabalhador é incompleto, também o é o saber teórico que precisa estar, permanentemente, referido ao concreto. A separação entre concepção e execução do trabalho significa um ônus também para o capital. Burowoy vai além nesta reflexão:

contribuição para o campo da Saúde do Trabalhador no Brasil".

11 Convencionou-se chamar de Modelo Japonês o sistema de gestão da produção que se originou na Toyota entre 1948 e 1975 desenvolvido por Taiichi Ohno. 


\section{Trabalhonecessário}

Issn: 1808 - 799X

ano 13, número $20-2015$

a tentativa de aplicar o taylorismo leva os trabalhadores a recriar a unidade entre concepção e execução, porém, em oposição às regras do capital. Mais do que uma separação entre concepção e execução, há uma separação entre a concepção do capital e a concepção dos trabalhadores, uma separação entre 0 conhecimento dos trabalhadores e o conhecimento do capital (Burowoy apud Apple, 1989, p. 88).

A complexidade do saber do trabalhador pode ser depreendida nos debates acima. Como aponta Franzoi (1991, 2009), esse saber é referido por alguns como "Saber Prático", "Saber Informal", por outros como "Qualificações Tácitas" ou, com Wallon (Dantas, 1993) "saber/teoria em ato". O conceito de "qualificações tácitas" é introduzido por Wood "para enfatizar os limites da degradação do trabalho e como as qualificações, embora parciais, são exercitadas mesmo nos trabalhos aparentemente desqualificados" (1989, p. 1). As categorias saber e subjetividade ganham, pois, relevância.

Quando Castoriadis pergunta: "Pelo contrato de trabalho, o operário vende sua força de trabalho à Empresa. Mas o que é essa força de trabalho? Será que o operário vende seu "tempo"? Mas o que é esse tempo?" (1985, p. 100), poder-seia responder recorrendo a Marx, que "o tempo é o espaço em que se desenvolve o ser humano" (apud Enguita, 1989, p. 9). Ou seja, este tempo é denso. Denso de subjetividade do trabalhador, incluído aqui seu saber, em parte apropriado pelo capital, em parte não.

Seguindo as trilhas abertas por tais estudos, vibrando com as greves dos metalúrgicos do $A B C$, no final da década de 1970, e com a convicção de que o setor industrial ditava as tendências no mundo do trabalho, vários de nós elegemos a fábrica capitalista como lócus de pesquisa, em busca do processo de trabalho e, no centro dele, do sujeito. Tratava-se de resgatar, por detrás de ideias como a

'separação entre execução e concepção', o 'homem como apêndice da máquina', um trabalhador, individual e coletivo, que luta contra sua objetificação. Ao invés de um ser passivo diante da máquina que condensa um saber, outrora seu, um ser ativo que 


\section{Trabalhonecessário}

Issn: 1808 - 799X

ano 13, número $20-2015$

constrói conhecimento, e a cada nova situação se lança novos desafios (Franzoi, 2006, p. 191).

Nossa referência conceitual era Braverman (1978) e os estudos de Coriat (1976), dentre outros, que afirmavam

a ideia da determinação social da técnica [...]: a introdução de novas formas de organização do trabalho traria um progresso no sistema de controle dos trabalhadores, implantado segundo o interesse do capital, [...] [vis à vis] à 'resistência operária"' (Santos, 2000 , p. 120).

Tal referencial, ao enfatizar o determinismo da técnica e apenas a resistência dos trabalhadores, induziu a um limite na análise, segundo alguns. $\mathrm{Na}$ sociologia do trabalho, por exemplo, o texto de Nadya Castro e Antônio Guimarães (1991) Além de Braverman, depois de Burowoy é paradigmático. Nele, os autores já apontavam os limites da Bravermania e os avanços de Burowoy. Estes consistiam nas suas análises por dentro do processo de trabalho e na introdução do conceito de relações na produção, aquelas que aí acontecem. Mas Castro e Guimarães (1991) apontavam que estes avanços ainda não eram suficientes:

a questão não é apenas 'trazer de volta os trabalhadores', como escreveu Burawoy, mas reintroduzir o 'sujeito desaparecido', como sugeriu Thompson (1990). [...] O arcabouço analítico burawoyniano ressente-se da ausência de dimensões centrais, como a divisão sexual do trabalho, as relações étnicas e de gênero (1991, p. 10 e 13).

Para tanto, Castro e Guimarães evocam Hirata e Zarifian (1990) segundo os quais, por um lado, o êxito do Modelo Japonês, no país de origem, não se explica, exclusivamente, pelo sistema de emprego vitalício, mas por relações de gênero tecidas fora da fábrica. Por outro, o enraizamento de práticas e saberes voltados para a inovação, nos chãos de fábrica, só são conseguidos graças "ao estímulo à competência coletiva, isso elude comportamentos individuais de 
Issn: 1808 - 799X

ano 13 , número $20-2015$

retenção de saberes, comuns nas culturas que apenas valorizam o êxito e a competência individuais" (Castro; Guimarães, 1991, p. 13 [c1]).

Eloisa Helena Santos ${ }^{12}$, por sua vez, assim expressa esses limites, ao referir-se a sua própria dissertação, defendida em 1985:

Minha análise reduz a riqueza da vida na fábrica à resistência dos trabalhadores à organização capitalista do trabalho [...] que não permite pensar o papel importante dos trabalhadores na transformação da produção, além da sua própria transformação neste processo. A vida em toda a sua dimensão se esvai pelo poder do interesse do capital (Santos, 2000, p. 120-121).

Santos busca ultrapassar tais limites, na sua tese de doutorado,

recuperando uma dimensão positiva do trabalho e, em consequência, de seus protagonistas. [...] O trabalhador não é um mero executante determinado pelo seu lugar nas relações sociais e pelos dispositivos técnicos mas, também, um homem, sujeito vivente, com todo o horizonte de universalidade que isto implica (Santos, 2000, p. 121 e 123) ${ }^{13}$.

Para Santos (2003, p. 38), "a releitura de Marx tem levado a um esforço teórico-metodológico que procura resgatar as dimensões do sujeito e da subjetividade desprezadas nas análises centradas na Economia Política". Particularmente, a autora debruça-se sobre o epíteto trabalho concreto/trabalho abstrato.

O trabalho criador de valor é pois o trabalho geral abstrato (Marx, 1957) [...]. O entendimento de Marx de que 'o trabalho criador de valor é pois o trabalho geral abstrato' não impede [segundo a autora] que todo ato de trabalho seja ao mesmo tempo a obra de homens concretos que mobilizam suas capacidades na produção

12 Selecionaram-se aqui alguns poucos excertos que nos pareceram relevantes para compreender a abordagem da autora, considerando a brevidade deste texto. Para um aprofundamento de suas ideias ver Santos $(2000,2003)$.

13 Podemos reconhecer aqui a referência a Georges Canguilhem. Ver Canguilhem (2001) Meio e normas do homem no trabalho sobre a análise que faz de duas questões: a "das relações do homem e do meio e a questão da determinação e da significação das normas humanas" ( $p$. 114). 


\section{Trabalhonecessário}

Issn: 1808 - 799X

ano 13 , número $20-2015$

de objetos úteis e diversificados'. [...] Marcada esta distinção entre trabalho abstrato e trabalho concreto, utilizo o conceito de 'ato', de Lucien Sève [...]. No ato, concreto e abstrato se misturam e se contradizem. [...] $\mathrm{O}$ ato de trabalho pressupõe sempre, da parte daqueles que o realizam, a criação de um optimum de condições vitais face às configurações produtivas que as ignoram. $O$ que seria considerado como resistência passiva significa, ao contrário, uma reapropriação criativa de um meio de trabalho contra uma evolução e uma degradação das funções vitais (Santos, 2000, p. 122).

E prossegue, citando Yves Schwartz:

Entretanto, 'julgar que, em certos momentos, nós podemos subsumir todo o pensamento do trabalho sob a forma unicamente abstrata é crer que, no homem, a humanidade produtora poderia se colocar entre parênteses; que cessam em horas fixas as potencialidades de apropriação das conjunturas concretas; que a parte de comensurabilidade de destino entre os homens é regularmente quebrada' (Schwartz, 1988, apud Santos, 2000, p. 124).

Assim como Santos, Daisy Cunha também busca na ergonomia da atividade francesa e na ergologia o aprofundamento das categorias marxistas, para superar impasses teóricos. Com base nessas vertentes, Cunha se propõe a aprofundar o trabalho através da categoria atividade.

A autora reconhece como um dos principais aportes da psicologia soviética, para o campo de estudos trabalho e educação o conceito de atividade, desenvolvido por Leontiev, a partir da obra de Marx.

O termo 'atividade', importante contribuição dessa psicologia, vem sendo reapropriado por certa psicologia do trabalho francesa de cunho histórico e sócio-cultural, pela chamada ergonomia da atividade e pela ergologia, propiciando reconhecimento do trabalho como experiência histórica e sócio-cultural (Cunha, 2005, p. 115).

Acrescenta a autora que essa psicologia permite "compreender o fenômeno educativo por meio de novas bases teóricas, evidenciando a dimensão educativa 


\section{Trabalhonecessário}

Issn: 1808 - 799X

ano 13, número $20-2015$

da experiência humana do trabalho apreendido como uma atividade" (Cunha, 2005, p. 116).

O que essas duas vertentes, em especial a ergologia, vão propor, como consequência da adoção da categoria atividade, é um exame clínico do trabalho.

Trabalho para a ergologia é atividade humana vivida no espaço de trabalho, o que the rende especificidades: atividade industriosa dirá Yves Schwartz. Dessa perspectiva, olhando o trabalho com uma lupa lá no seu cotidiano, a maneira como os homens produzem bens e ao mesmo tempo se produzem a si mesmos pode revelar o educativo presente na experiência de trabalho (Cunha, 2005, p. 8).

Com esta lupa sobre o trabalho e tomando por objeto de estudo a "atividade industriosa", a ergologia traz uma importante contribuição para compreender a natureza dos saberes produzidos, mobilizados e/ou modificados em situação de trabalho pelo trabalhador.

Segundo Schwartz,

toda atividade de trabalho encontra saberes acumulados nos instrumentos, nas técnicas, nos dispositivos coletivos; toda situação de trabalho está saturada de normas de vida, de formas de exploração da natureza e dos homens uns pelos outros (2003, p. 23).

No entanto, uma vez que, "este concentrado de história é sempre inacabado, lacunar, [...] 'renormalizações' incessantes reaparecem em todos os lugares onde os grupos humanos se mobilizam para produzir", (Schwartz, 2003, p. 24) fazendo com que jamais duas situações de trabalho sejam idênticas. Para tais renormalizações, os trabalhadores mobilizam seus saberes, que o autor define como aqueles que 


\section{Trabalhonecessário}

Issn: 1808 - 799X

ano 13, número $20-2015$

espraiam-se, sem descontinuidade, das formas de inteligência incorporadas no nosso corpo até os patrimônios de experiência pensados, raciocinados, transmissíveis. Eles vão de aprendizagens não-conscientes, não-expressos em linguagem, dificilmente perceptível, até as maneiras de fazer socializadas, justificáveis, manifestas (Schwartz, 2003, p. 24).

Assim,

a partir da tomada em consideração das inúmeras variabilidades que proliferam mesmo aí onde tudo foi, em teoria, exaustivamente previsto, nós somos conduzidos a mensurar a importância do tratamento, por todos os tipos de trabalhadores, de tudo isto que faz com que um meio técnico não seja, jamais, a reprodução standard de concepções, de protocolos, de procedimentos, pensados por outros, fora de um contexto histórico e geográfico preciso (Schwartz, 2003, p. 25).

O suposto aqui é que é preciso "levar a sério o trabalho que acreditamos ser simples" (Schwartz; Durrive, 2007). Este é o mesmo suposto de outros autores, que partem de outras vertentes teóricas. Estão entre eles Jarbas Barato e Mike Rose que desenvolvem estudos sobre diferentes grupos profissionais, com achados bastante convergentes. Barato considera que teoria e prática são categorias inadequadas para explicar a natureza do saber humano. Ele compreende o 'fazer-saber' como uma dimensão epistemológica cuja origem e fundamento é a própria ação, não um pensar que a antecede. O objetivo do autor com seu estudo

foi mostrar que o rótulo "prática" esvazia de significado o saber técnico. Por outro lado, quando se reconhece o status específico da técnica como saber, é possível entender as atividades produtivas como um conhecimento que engaja trabalhadores em fazeres inteligentes (Barato, 2003, p. 17).

Rose, por sua vez, advoga em favor de um olhar mais atento sobre o trabalho comum, para extrair lições sobre a inteligência do trabalhador. As conceituações que normalmente opõem 'trabalhador de macacão, trabalhador de 


\section{Trabalhonecessário}

Issn: 1808 - 799X

ano 13, número $20-2015$

colarinho branco'; 'trabalho mental, trabalho mental'

reafirmam preconceitos muito antigos sobre determinadas ocupações e fazem com que deixemos de observar muitas coisas no trabalho diário: os processos mentais que possibilitam serviços; a estética do trabalho físico; a complexa interação do social e do mecânico; a coreografia da mão, dos olhos, dos ouvidos, do cérebro; a presença indispensável, em sua execução, da abstração, do planejamento e da resolução de problemas (Rose, 2007, p. 31).

Se anteriormente apontamos a forma como pesquisadores utilizam as categorias ato e atividade para aprofundar os conceitos de trabalho abstrato e trabalho concreto, esses últimos trabalhos apontam mais um aprofundamento necessário: aquele relativo aos conceitos de trabalho simples-trabalho concreto, que convoca, por seu turno, análises sobre saberes profissionais ${ }^{14}$.

\section{Saberes e Competências: O Saber do Trabalhador aos Pedaços}

Se nos anos 1980 e início dos 1990, como vimos anteriormente, somos convocadas pelos sindicatos a contribuir para a compreensão das mudanças oriundas da implementação da reestruturação produtiva, na metade dos 1990, somos provocadas pelas políticas neoliberais a dar conta de uma nova categoria: competências. No bojo dessas políticas, juntamente com o decreto 2208/1997 que separou o ensino médio do técnico - as competências têm lugar de destaque e com elas o saber dos trabalhadores vem na única fórmula através da qual o capital sabe se apropriar do trabalhador: aos pedaços, para dele se apropriar por inteiro. O saber do trabalhador vem então travestido de saber fazer, saber ser, saber conviver, saber conhecer ${ }^{15}$, esvaziando-o de sentido epistemológico e

14 Maria Clara Bueno Fischer (2012) e Naira Lisboa Franzoi, esta quando afirma a "complexidade do trabalho simples" (2011), têm se debruçado sobre o tema estudando diferentes grupos profissionais.

15 Unesco. 
Issn: 1808 - 799X

ano 13 , número $20-2015$

político. É aqui que se localizam os trabalhos de Marise Ramos (2001), Lucilia Machado (2007), Lucie Tanguy (1997), Neise Deluiz (2001), Yves Schwartz (1998), Silvia Manfredi (1999), Acácia Kuenzer (2003), dentre outros ${ }^{16}$.

\section{Os Saberes do Trabalho "Para Além dos Muros” da Fábrica Capitalista}

Lembremos que vibrávamos com as greves dos metalúrgicos do $\mathrm{ABC}$; os modelos de gestão vinham da indústria. Ideologicamente, inspirávamo-nos em Gramsci (1980) que afirma que a hegemonia vem da fábrica. Falávamos do operário fabril. Mas havia uma terceirização da economia; o desemprego se instalava, o que fez com que Nadya Castro (2002) propugnasse "por uma sociologia do desemprego".

Gaudêncio Frigotto traz para o GT Trabalho-Educação, no contexto dos anos 90, uma reflexão teórico-metodológica que continua atual, sobre a relevância - e especificidades - de o Grupo pesquisar os diversos temposespaços do trabalho. Dizia ele:

As pesquisas sobre trabalho-educação podem encontrar um terreno fértil ao buscar desvendar, ao mesmo tempo, as mediações de segunda ordem, ordenadas pelo capital, cujo horizonte teórico é de natureza estrutural-funcional, e os elementos e indícios de novas relações sociais e formativas, cujo fundamento são as mediações de primeira ordem que vinculam trabalho e educação, cultura e tecnologia, como expressões de "um novo industrialismo" e de melhoria da qualidade de vida e busca de dilatação de tempo de liberdade - de fruição, de gozo e de realização humana (Manacorda, 1990, 1991). Pesquisas que se pautem numa perspectiva histórica, necessariamente, vincularão formas sociais da produção material da existência ou formas sociais de produção da "sobrevivência", presentes nos movimentos e lutas sociais e processos de formação humana. $O$ surgimento de uma ampla literatura sobre economia popular (Coraggio, 1994, 1995; Razeto, 1993; Singer, 1996; Tiriba, 1997; Villasante, 1996; Nuñez, 1995), sinaliza, por um lado, uma materialidade de formas de sobrevivência, organização e relações

16 A problemática da relação entre saberes e competências é complexa e merece maior desenvolvimento, o que não foi possível realizar neste texto. 


\title{
Trabalhonecessário
}

Issn: 1808 - 799X

ano 13, número $20-2015$

de trabalho diversas das formas dominantes e resultantes da exclusão do mercado formal de trabalho e, de outro, o desafio de entender os processos de formação humana articulados a esta nova realidade (Frigotto, 1998, p. 47).

Em outro momento do mesmo artigo, continuando sua análise, afirma:

\begin{abstract}
Apreender as mediações, no plano econômico-social, cultural, simbólico e educativo, que articulam os interesses e as lutas da classe trabalhadora é, sem dúvida, o desafio crucial do GT Trabalho-Educação da ANPED. Os recortes temáticos tanto podem emergir da compreensão do núcleo contraditório das formas que assume a relação capital-trabalho no contexto de aceleração da sua dinâmica global, como das formas de organização do trabalho e processos educativos que emergem da organização dos excluídos deste processo. Talvez este seja um dos aspectos a que o nosso GT tenha dado pouca atenção. A importância que tem assumido o MST vem despertando interesse de pesquisa de vários doutorandos e mestrandos, assim como a configuração daquilo que vem se denominando de economia popular e estratégias de trabalho/sobrevivência. Trabalhar os limites e virtualidades destas realidades postas pelo movimento histórico presente, nos diferentes movimentos sociais, parece-nos um desafio importante e necessário de ser enfrentado (Frigotto, 1998, p. 50).
\end{abstract}

Como as mediações de primeira e segunda ordem têm sido tratadas nas pesquisas no campo trabalho e educação, especialmente naquelas dedicadas à cultura e/ou aos saberes do trabalho nas suas mais diversas manifestações?

Embora o predomínio das investigações sobre saberes do trabalho seja, desde então, no trabalho industrial na empresa capitalista, a ele não se reduzem. A emergência de experiências de trabalho associado, especialmente a partir do contexto da crise dos anos 90 na América Latina, e, em especial, no Brasil, levará alguns investigadores a tomá-las como objeto de estudo. Alguns de nós estávamos interessados em entender outras experiências de trabalho, suas culturas, suas pedagogias e seus saberes. Em 2001, Lia Tiriba, pesquisadora do GT Trabalho e Educação, publica "Economia popular e cultura do trabalho: pedagogia(s) da produção associada". Toma o trabalho como princípio educativo 
Issn: 1808 - 799X

ano 13, número $20-2015$

como referência central para sua análise. Está interessada, como Acácia Kuenzer (1989), na Pedagogia do Trabalho, no que acontece em outros tempos e espaços econômico-culturais, em que outras relações de trabalho acontecem no interior da sociedade de classe. Alguns pesquisadores da área Trabalho e Educação terão, então, como objeto de investigação experiências de trabalhadores em fábricas recuperadas ou ocupadas, associações e cooperativas de trabalhadores que emergem na crise dos anos 90. Além dessas, outras experiências de economia popular e de comunidades tradicionais serão pesquisadas.

$\mathrm{Na}$ medida em que os integrantes destas unidades econômicas aprendem os conhecimentos específicos para produzir os bens materiais para sua sobrevivência, aprendem também os valores, os comportamentos que são necessários para o estabelecimento de determinadas relações de produção. Vislumbramos uma pedagogia da produção associada que contribua não apenas para questionar e driblar a perversa lógica excludente do mercado capitalista, mas também para cultivar - no interior da sociedade de classes - os germes de uma cultura do trabalho que contrarie a lógica do capital. [...] Reivindicamos a articulação entre práxis produtiva e práxis educativa, o que requer, dentre outros, o (re)encontro entre trabalho e educação, economia popular e educação popular (Tiriba, 2007, p. 93).

Reflexões a respeito dos saberes nessas outras experiências de trabalho resultam na elaboração, por exemplo, do verbete "saberes do trabalho associado" (Fischer; Tiriba, 2009) em que é incorporada parte da reflexão dos pesquisadores do GT - algumas delas expostas neste texto - mas integrando outras elaborações teórico-metodológicas, como é o caso da educação popular e dos 'saberes c 166 experiência feitos'. Saberes dos trabalhadores que instituem e são instituídos em formas de trabalho associado - são sujeitos - entram, portanto, em cena na pesquisa no Campo ${ }^{17}$.

17 O tema dos saberes do trabalho associado merece maior detalhamento e exposição, o que não foi possível no escopo deste texto. 


\section{Trabalhonecessário}

Issn: 1808 - 799X

ano 13, número $20-2015$

\section{Saberes do Trabalho: Diálogos entre Pares}

O grupo de pesquisa Trabalho, Educação e Conhecimento, do qual fazemos parte e atualmente coordenado pela UNISINOS e pela UFRGS, reúne pesquisadores e pesquisadoras de várias universidades do país. Foi criado em 2008 com o objetivo de aprofundar investigações sobre as interfaces entre diferentes experiências de trabalho, educação e conhecimento, priorizando como objeto de estudo os saberes do trabalho. As Jornadas sobre Produção e Legitimação de Saberes para e no Trabalho, que veem sendo realizadas desde 2006, deram origem ao Grupo. É um espaço para aprofundamento de temáticas e referenciais teóricos utilizados nas pesquisas, produzindo uma rica interlocução entre pesquisadores e também trabalhadores, com os quais estabelecemos relação nas investigações ${ }^{18}$.

Há na tradição marxiana uma potência que alimenta o Grupo. A centralidade do trabalho na formação humana é o suposto das pesquisas e vários de nós têm buscado, em diálogo com outras abordagens teóricas, investigar tal temática. Há um preocupação constante com o entendimento das relações entre sujeito e estrutura. Daí as preocupações em retomar/aprofundar categorias como atividade de trabalho e cultura. Neste sentido, a abordagem da história e de classe social, em Thompson (1982) e, por suposto, o tratamento que o mesmo dá à categoria experiência, têm sido objetos de estudo entre alguns do Grupo. Em diálogo com tal tradição, há os que exploram as contribuições da ergologia no que diz respeito à atividade de trabalho e sua relação com a produção de saberes e valores.

Pesquisadoras deste Grupo estão aprofundando as interfaces entre as categorias gênero, raça e etnia e trabalho. Esses estudos têm enriquecido as

18 Três dossiês temáticos sobre o tema saberes e trabalho já foram produzidos; dois pela revista Educação Unisinos (2006; 2009) e um no periódico Trabalho \& Educação (2013), com produções científicas de membros do Grupo e de convidados. O conteúdo dos artigos ilustram as preocupações e reflexões que têm atravessado os debates do Grupo como também dão uma ideia sobre a complexidade e abrangência do tema "saberes do trabalho". 


\section{Trabalhonecessário}

Issn: 1808 - 799X

ano 13, número $20-2015$

análises sobre os saberes do trabalho porque aprofundam a problemática da invisibilidade dos saberes das mulheres, na perspectiva de seu empoderamento.

Relevante é, também, o fato de que há pesquisas no referido Grupo que abordam os temas da cultura e saberes do trabalho nas formas de produção associada, trazendo novos desafios teórico-metodológicos à pesquisa. É o caso, por exemplo, de Lia Tiriba, Edson Caetano e Maria Clara Bueno Fischer ${ }^{19}$. Nas experiências de trabalho na produção associada forjam-se novas culturas do trabalho e coloca-se o desafio de analisar como as mediações de primeira e segunda ordem se manifestam nas experiências de trabalho associado e suas consequências para a pesquisa sobre saberes do trabalho ${ }^{20}$.

Por fim, é importante chamar a atenção para o fato de que há um material profícuo para aprofundamento de diálogos sobre o tema em autores, participantes do GT Trabalho Educação ou não. Veja-se, por exemplo, o trabalho de pesquisa sobre os saberes de pescadores investigado por Doriedson Rodrigues (2012) professor da UFPA, na perspectiva do materialismo histórico e dialético e situando o tema no contexto da luta de classes. O autor se utiliza do conceito de saberes sociais (Grzybowski, 1986) para analisar os saberes dos pescadores. Na Argentina, Nicolas Arata e Maria Luz Ayuso $(2009,2013)$ têm se debruçado sobre a história do artesanato naquele país e extraído consequências para aprofundar os saberes do trabalho. Desse país há também a contribuição de Adriana Puigrós sobre o que esta denomina de saberes socialmente produtivos. Mike Rose (2007), nos Estados Unidos, tem investigado o 'saber no trabalho' analisando os saberes profissionais de trabalhadores ditos não qualificados, visibilizando a inteligência do trabalhador. Jarbas Barato (2004), a partir das mesmas matrizes teóricas que Rose, tem se dedicado a buscar uma didática para o ensino profissional. Marise Ramos, a partir dos estudos de Telmo Caria e seu grupo (2005), tem feito

19 Ver pesquisa coordenada por Lia Tiriba intitulada Trabalho, educação e produção associada - Fios do "econômico" e do "cultural" na tessitura de relações sociais não capitalistas. (NEDDATE), da qual fazem parte os professores citados, bem como orientandos e orientandas.

20 Estas questões são abordadas no artigo, deste dossiê, de Lia Tiriba, que compôs a mesa Culturas do trabalho, movimentos sociais e produção de saberes. 


\section{Trabalhonecessário}

Issn: 1808 - 799X

ano 13 , número $20-2015$

incursões numa abordagem etnográfica para conhecer os saberes profissionais. Essas são apenas algumas indicações de trabalhos de pesquisa com os quais temos feito interlocuções que servem para chamar a atenção sobre a fertilidade do tema genericamente denominado saberes do trabalho.

\section{Considerações Finais}

Consoante com o Encontro, o texto teve por objetivo realizar um mapeamento do tema saberes do trabalho, pontuando-se, sempre que pertinente, sua inserção na história do GT Trabalho-Educação, da Anped. Para tal, foi necessário retomar e analisar caminhos, tempos e espaços de produção das ideias que circulam na área, contextualizando-as e historicizando-as. Identificamse presenças, ausências, continuidades e/ou descontinuidades na investigação do tema. Ainda consoante com o II Intercrítica, buscou-se com isso contribuir para atualizar a agenda de estudos e debates do GT.

O campo teórico em torno dos saberes do trabalho está em construção. A tarefa de mapeamento abrangente, sistemático e analítico do tema, em nível nacional e internacional, é tarefa ainda por ser feita. Alguns dos conceitos implicados, conforme descrito no texto, já têm certo desenvolvimento, ainda que demandem aprofundamento. Outros têm um desenvolvimento ainda incipiente. Ao longo do texto, apontamos alguns: os pares dialéticos trabalho abstrato - trabalho concreto; trabalho prescrito - trabalho real; trabalho simples - trabalho complexo; a categoria atividade e ato. Certamente não esgotam o tema, mas todos el 169 compõem uma agenda de estudos e debates. Dar conta dela supõe, entre outras coisas, a ampliação do diálogo entre os pares, com diferentes abordagens e com outros campos de saber.

\section{Referências Bibliográficas}

APPLE, Michael. Educação e Poder. Porto Alegre: Artes Médicas, 1989.

ARATA, Nicolás. Los saberes del oficio: notas conceptuales. Trabalho \& 


\section{Trabalhonecessário}

Issn: 1808 - 799X

ano 13 , número $20-2015$

Educação, Belo Horizonte, v. 22, n. 3, p. 149-164, set./dez. 2013.

ARROYO, Miguel. Educação e Trabalho. In: Reunião Anual da Associação Nacional de Pós-Graduação em Pesquisa em Educação. Rio de Janeiro: ANPED, 1981.

AYUSO, Maria Luz; ARATA, Nicolás. De artesanos a trabajadores: dos estudios sobre la regulación de los saberes del trabajo. Educação Unisinos, São Leopoldo, v. $13, \quad$ n. 3 , p. 211-219, set./dez. 2009. Disponível em: <http://revistas.unisinos.br/index.php/educacao/article/view/4948> Acesso em: 03 dez. 2014.

BARATO, Jarbas. Educação Profissional. Saberes do ócio ou saberes do trabalho? São Paulo: Editora SENAC, 2004.

. Educação profissional: saberes do ócio ou saberes do trabalho? São

Paulo: Ed. SENAC, 2003.

BRASÍLIA. Lei $n^{\circ}$ 9.394, de 20 de dezembro de 1996. Estabelece as diretrizes e bases da educação nacional. Disponível em: $<$ http://portal.mec.gov.br/seed/arquivos/pdf/tvescola/leis/lein9394.pdf > Acesso em: 03 dez. 2014,

BRAVERMAN, Harry. Trabajo y Capital Monopolista. México: Nuestro Tiempo, 1978.

CANGUILHEM, Georges. Meio e normas do homem no trabalho. Proposições, v. 12, n. 2-3, p. 35-36, jul./nov. 2001.

CARIA, Telmo et al. (Orgs.). Saber Profissional. Lisboa: Almedina, 2005.

CASTORIADIS, Cornelius. A Experiência do Movimento Operário. São Paulo: Brasiliense, 1985.

CASTRO, Nadya Araújo; GUIMARÃES, Antônio Sérgio Alfredo. Além de Braverman, depois de Burawoy: Vertentes analíticas na sociologia do trabalho. Revista Brasileira de Ciências Sociais, Rio de Janeiro, v. 6, n. 6, p. 44-52, 1991.

CASTRO, Nadya. Por uma sociologia do desemprego. Revista Brasileira de Ciências Sociais, São Paulo, v. 17, n. 50, out. 2002.

CORIAT, Benjamin. Ciência, técnica y capital. Madrid: Blume, 1976.

CUNHA, Daisy Moreira. Aspectos da estrutura e do desenvolvimento da atividade humana em Aléxis Leontiev. In: Aranha, Antônia Vitória; Cunha, Daisy Moreira; Laudares, João Bosco (Orgs.). Diálogos sobre o trabalho: perspectivas multidisciplinares. Campinas: Papirus, 2005.

DANTAS, Heloysa. Do ato motor ao ato mental: a gênese da inteligência segundı 170

Wallon. In: De La Taille et al.. Piaget, Vygotsky e Wallon: teorias psicogenética o em discussão. São Paulo: Summus, 1993.

DELUIZ, Neise. O modelo das competências profissionais no mundo do trabalho e na educação: implicações para o currículo. Boletim Técnico do SENAC, Rio de Janeiro, v. 27, n. 3, set./dez. 2001. Disponível em: <http://www.senac.br/informativo/BTS/273/boltec273b.htm> Acesso em: 01 out. 2014.

DURRIVE, Louis; SCHWARTZ, Yves. Glossário da ergologia. Laboreal, Torino, v. 4, n.1, p. 23-28, jul. 2008. Disponível em: 


\section{Trabalhonecessário}

Issn: 1808 - 799X

ano 13, número $20-2015$

$<$ http://laboreal.up.pt/files/articles/2008_07/pt/23-28pt.pdf> Acesso em: 01 out. 2014.

ENGUITA, Mariano. A Face Oculta da Escola. Porto Alegre: Artes Médicas, 1989.

FISCHER, Maria Clara Bueno; TIRIBA, Lia. Saberes do trabalho associado. In: Cattani, Antonio David et al. (Orgs.). Dicionário Internacional da Outra Economia. Coimbra/São Paulo: Edições Almedina; Almedina Brasil, 2009.

FISCHER, Maria Clara Bueno. Projeto de pesquisa: Formação de adultos para e no trabalho associado: atividade de trabalho, profissão e biografias: 2012-2015. Porto Alegre: UFRGS, 2012. (mimeo).

FRANZOI, Naira Lisboa. O modelo japonês e o conhecimento informal dos trabalhadores no chão de fábrica. 1991. 139f. Dissertação (Mestrado em Educação) - UFRGS, Porto Alegre.

. O conhecimento informal dos trabalhadores no chão de fábrica. Revista Educação Unisinos, São Leopoldo, v. 13, n. 3, p. 189-200, 2009.

. A complexidade do trabalho simples: trajetórias saberes e identidades profissionais. Relatório Pós Doutorado Senior - NJCU, New Jersey; UFRGS, Porto Alegre. Dez. 2011. (mimeo).

FREYSSENET, M.; HIRATA, Helena. Mudanças Tecnológicas e Participação dos Trabalhadores: Os Círculos de Controle de Qualidade no Japão. Revista de Administração de Empresas, Rio da Janeiro, v. 2, n. 3, p. 25-43, jun./set. 1985.

FRIGOTTO, Gaudêncio. Educação, crise do trabalho assalariado e do desenvolvimento: teorias em conflito. In: Educação e crise do trabalho: perspectivas de final de século. Petrópolis: Vozes, 1998. p. 25-54.

GOMEZ, Carlos M. et al..Trabalho e Conhecimento: Dilemas na Educação do trabalhador. São Paulo: Cortez, 1987.

GRAMSCI, Antonio. Maquiavel, a política e o Estado moderno. 4. ed. Rio de Janeiro: Civ. Brasileira, 1980.

GRZYBOWSKI, Cândido. Esboço de uma alternativa para pensar a educação no meio rural. Contexto \& Educação, UNIJUÍ, ano 1, n. 4, p. 47-59, out./dez. 1986.

HIRATA, Helena; ZARIFIAN, Philipe. Force et fragilité du modèle japonais. Mensuel M, Paris, n. 37, p. 1-9, mai. 1990.

KUENZER, Acácia. Competência como Práxis: os dilemas da relação entre teoria e prática na educação dos trabalhadores. Boletim Técnico do Senac, Rio de Janeiro, v. 29, n. 1, p. 16-27, 2003. Disponível em:

<www.senac.br/BTS/291/boltec291b.htm> Acesso em :01 out. 2014.

INEP/MEC, 1991.

Educação e trabalho no Brasil: o estado da questão. Brasília. . Pedagogia da Fábrica. São Paulo: Cortez, 1989.

A apropriação do saber sobre o trabalho: um direito do trabalhador. Em Aberto, Brasília, ano 5, n. 30, abr./jun. 1986.

MACHADO, Lucília Regina de Souza. Saberes Tecnológicos, Teoria da Atividade e Processos Pedagógicos. Trabalho \& Educação, Belo Horizonte: UFMG, v. 22, p. 77-93, 2007.

MANFREDI, Sílvia Maria. Trabalho, qualificação e competência profissional: das 


\section{Trabalhonecessário}

Issn: 1808 - 799X

ano 13, número $20-2015$

dimensões conceituais e políticas. Educação \& Sociedade, Campinas, v. 19, n. 64, set. 1999. Disponível em: <http://www.scielo.php?script=sci_arttext=so101=pt> Acesso em: 01 abr. 2010.

MUNIZ, Hélder Pordeus et. al.. Ivar Oddone e sua contribuição para o campo da Saúde do Trabalhador no Brasil. Rev. bras. Saúde ocup., São Paulo, v. 38, n.128, p. 280-291, 2013.

ODONE, Ivar. Experiencia Laboral. Laboreal, Torino, v. 3, n. 1, p. 52-53, jul. 2007. Disponível em: <http://laboreal.up.pt/pt/articles/experiencia/> Acesso em: 01 out. 2014.

RODRIGUES, Doriedson do Socorro. Saberes sociais e luta de classes: um estudo a partir da colônia de pescadores artesanais z-16 - Cametá/Pará. 2012. 337f. Tese (Doutorado em Educação) - UFPR, Belém. Disponível em: <http://www.ppged.belemvirtual.com.br/arquivos/File/tese_doriedson_pdf.pdf> Acesso em: 05 out. 2014.

ROSE, Mike. O saber no trabalho: valorização da inteligência do trabalhador. São Paulo: Editora SENAC, 2007.

SANTOS, Eloisa Helena. Ciência e cultura: uma outra relação entre saber e trabalho. Trabalho \& Educação, Belo Horizonte, n. 7, p. 120-130, jul/dez, 2000.

Saber. In: Fidalgo, Fernando; Machado, Lucília (EE.). Dicionário da

Educação Profissional. Belo Horizonte: UFMG, 2000.

Processos de produção e legitimação de saberes no trabalho. In:

Gonçalves, Luiz Alberto Oliveira (Org.). Currículo e políticas públicas. Belo Horizonte: Autêntica Editora, 2003. p. 29-40.

SCHWARTZ, Yves; DURRIVE, Louis (Org.). Trabalho e ergologia: conversas sobre a atividade humana. Niterói: UFF, 2007.

SCHWARTZ, Yves. Trabalho e saber. , v. 12, n. 1, p. 21-33, jan.jun. 2003.

Os ingredientes da competência: Um exercício necessário para uma questão insolúvel. Educação \& Sociedade, Campinas, v. 19, n. 65, dez. 1998. Disponível em: <http://dx.doi.org/10.1590/S0101-73301998000400004> Acesso em: 01 out. 2014.

TIRIBA, Lia. Educação popular e pedagogia(s) da produção associada. Cad. Cedes, Campinas, v. 27, n. 71, p. 85-98, jan./abr. 2007.

. Economia Popular e Cultura do Trabalho: pedagogia(s) da produção associada. Ijuí: Editora UNIJUI, 2001.

THOMPSON, Edward. A Formação da Classe Operária Inglesa. São Paulo: Paz e Terra, 1982.

TREIN, Eunice; CIAVATTA, Maria. O percurso teórico e empírico do GT Trabalho e Educação: uma análise para debate. Revista Brasileira de Educação, n. 24, p. 140-164, set. /out. /nov./dez. 2003.

WOOD, Stephen. The Japanese Management Model (To appear in Work and Occupations). 1989. (mimeo).

Recebido em 12 de outubro de 2014 Aprovado em 20 de dezembro de 2014 